\title{
Recurrent Diffuse Large B-Cell Lymphoma
}

National Cancer Institute

\section{Source}

National Cancer Institute. Recurrent Diffuse Large B-Cell Lymphoma. NCI Thesaurus.

Code C8852.

The reemergence of diffuse large B-cell lymphoma after a period of remission. 